\title{
CONSORCIAÇÃO DE FORRAGENS EM UM LATOSSOLO SOB PLANTIO DIRETO EM MATO GROSSO DO SUL
}

\section{FODDER IN INTERCROPPING ATTRIBUTE FUNCTION OF AN OXISOL UNDER NO-TILLAGE SYSTEM IN MATO GROSSO DO SUL STATE}

\author{
Máila Terra GIOIA ${ }^{1}$ \\ Rafael MONTANARI ${ }^{2}$ \\ Morel de Passos e CARVALHO ${ }^{2}$ \\ Pamela Kerlyane TOMAZ ${ }^{3}$ \\ Douglas Martins Pereira PELLIN ${ }^{4}$ \\ Flávio Carlos DALCHIAVON ${ }^{7}$ \\ Elói PANACHUKI ${ }^{5}$ \\ Lenon Henrique LOVERA ${ }^{6}$
}

\begin{abstract}
RESUMO
A adubação verde, utilizada tanto em sucessão como em rotação de culturas, é uma excelente prática conservacionista vegetativa do solo, uma vez que proporciona economia de fertilizantes; é descompactante, restabelece boas condições químicas, físicas e biológicas e, sobretudo, aumenta a produtividade vegetal. No ano agrícola de 2006/2007, na Fazenda de Ensino e Pesquisa da Faculdade de Engenharia de Ilha Solteira - FEIS/UNESP, situada nas condições do Cerrado Brasileiro $\left(22^{\circ} 23^{\prime} \mathrm{S}\right.$ e $\left.51^{\circ} 27^{\prime} \mathrm{W}\right)$, foi analisada a produtividade da massa seca da consorciação da forragem milheto+guandu (MSF) em função de atributos físicos do solo, resistência à penetração (RP), umidade gravimétrica (UG), umidade volumétrica (UV) e densidade do solo (DS) nas profundidades de $0-0,10 \mathrm{~m}, 0,10-0,20 \mathrm{~m}$ e $0,20-0,30 \mathrm{~m}$. Para tanto, foi instalada uma malha de dados contendo 117 pontos amostrais em um Latossolo Vermelho Distroférrico sob pivô central sob sistema plantio direto numa área experimental de $1600 \mathrm{~m}^{2}$. A análise estatística foi compreendida de análise descritiva inicial dos atributos, análise das correlações lineares simples e espaciais entre eles, e finalmente, análise geoestatística, objetivando, sobretudo, evidenciar condições que proporcionam aumento da produtividade agrícola. A produtividade da massa seca da forragem foi elevada, porém não se correlacionando espacialmente com os atributos estudados do solo. A umidade volumétrica e a densidade do solo foram os atributos do solo que mais se relacionaram para estimar a qualidade física do solo.

Palavras-chave: manejo do solo, adubação verde, geoestatística
\end{abstract}

\section{ABSTRACT}

Green manure, used both in succession as in crop rotation is an excellent practice vegetative soil conservation, since savings in fertilizers, is descompactante, restores good chemical, physical and biological and, especially, increases plant productivity. In the 2006/2007 crop year, the Teaching and Research Farm of the Faculty of Engineering of Single Island - FEIS / UNESP, located under the conditions of the Brazilian Cerrado $\left(22^{\circ} 23^{\prime} \mathrm{S}\right.$ and $\left.51^{\circ} 27^{\prime} \mathrm{W}\right)$, we analyzed the productivity of the mass dry forage intercropping millet + pigeonpea (MSF) in terms of physical attributes of soil penetration resistance (PR), gravimetric moisture (UG), volumetric water content (UV) and bulk density (DS) in depths of $0.00-0.10 \mathrm{~m}, 0.10-0.20 \mathrm{~m}$ and 0.20 to $0.30 \mathrm{~m}$. To that end, we installed a mesh data containing 117 sampling points in a Hapludox under center pivot under no-tillage in an experimental area of $1600 \mathrm{~m}^{2}$. Statistical analysis was comprised of descriptive analysis attributes of the original, simple linear correlation analysis and space between them, and finally, geostatistical analysis, aiming, above all, provide evidence of conditions that increase agricultural productivity. The productivity of forage dry matter was high, but not spatially correlated with the attributes of the soil studied. The water content and bulk density were the soil attributes that most closely related to estimate soil physical quality.

Key-words: crop rotation, physical attributes of soil penetration resistance e Hapludox.

\footnotetext{
1 Estudante de Pós-Graduação em Agronomia - UNESP de Ilha Solteira, Av. Brasil, Centro, 15385-000, Ilha Solteira, São Paulo, Brasil. e-mail: terragioia@hotmail.com

${ }^{2}$ Prof. Assistente da Universidade Estadual Paulista, UNESP de Ilha Solteira, Rua Monção, 226, 15385-000, Ilha Solteira, São Paulo, Brasil. email: rafamontana@hotmail.com, morel@agr.feis.unesp.br

3 Aluna de graduação em Zootecnia ; Departamento de Fitossanidade Rural e Solos; UNESP - FEIS - Universidade de Engenharia de Ilha Solteira; Passeio Monção 226; pamelazootecnia@hotmail.com

${ }^{4}$ Estudante de Pós-Graduação em Agronomia da Universidade Estadual de Mato Grosso do Sul, UEMS - Unidade de Aquidauana, Rod. Aquidauana-UEMS, km12, 79200-000, Aquidauana, MS, Brasil. e-mail: douglas.martins@agronomo.eng.br ${ }^{5}$ Prof. Adjunto da Universidade Estadual de Mato Grosso do Sul, UEMS - Unidade de Aquidauana, Rod. Aquidauana-UEMS, km12, 79200000, Aquidauana, MS, Brasil. e-mail: eloip@uems.br

${ }^{6}$ Estudante de Graduação em Agronomia da Universidade Estadual de Mato Grosso do Sul, UEMS - Unidade de Aquidauana, Rod. Aquidauana-UEMS, km12, 79200-000, Aquidauana, MS, Brasil.e-mail: lenon_lovera@hotmail.com

${ }_{7}^{7}$ Professor Doutor, Instituto Federal de Mato Grosso, Campus Campo Novo do Parecis, Departamento de Agronomia, Rodovia MT 235, Km 12, Zona Rural, Caixa Postal 100. CEP 78360-000. Campo Novo do Parecis (MT). E-mail: flavio.dalchiavon@cnp.ifmt.edu.br.
}

Scientia Agraria, Curitiba, v.14, n.1, p.41-50, Jan./Fev. 2013 


\section{INTRODUÇÃO}

O sistema plantio direto é um processo de semeadura que abrange práticas agrícolas interrelacionadas e interdependentes que incluem o não revolvimento do solo, a rotação de culturas, o uso de plantas de cobertura para formar e manter a palhada sobre o terreno, assim é importante a escoIha da cultura a ser empregada em rotação. Devese conhecer a espécie quanto a sua produção de massa seca e seu tempo de decomposição que interferem diretamente na qualidade e quantidade de palha sobre o solo, sendo esse um problema para região do cerrado brasileiro (Montanari et al., 2010).

A cultura do milheto tem a vantagem de ter uma taxa de decomposição baixa, é uma planta de clima quente, apresentando bom desenvolvimento em áreas de baixa precipitação pluviométrica com bom comportamento na maioria dos solos. No Centro-Oeste é implantado após a colheita das culturas anuais, para ser utilizado como pastagem no inverno. Já o feijão guandu tem uma taxa de decomposição alta, no entanto, com elevados teores de nitrogênio e capacidade de buscar fósforo em profundidade no solo. Por ter um sistema radicular pivotante e vigoroso que possibilita romper camadas compactadas assim foi chamado "arado biológico", também por seu potencial na conservação e melhorador químico do solo (Lupatini, 1996).

$\mathrm{Na}$ prática conservacionista da rotação de culturas deve-se utilizar a adubação verde como forma de reduzir custos com adubos, realizar a meIhoria da qualidade químico-física do solo e a proteção contra agentes climáticos durante a entressafra. A palha também tem a qualidade de reduzir a variação térmica e aumentar a retenção de água no solo nos períodos de estiagem (Andreotti et al., 2008).

A compactação do solo, muito comum em lavouras de plantio direto, causada pelo trânsito de máquinas e o não revolvimento do solo, afetam negativamente a qualidade física do solo interferindo no desenvolvimento das culturas principalmente quando o suprimento de água e nutrientes é insuficiente. A degradação física do solo pode ser evidenciada pela avaliação de atributos como a densidade e a resistência mecânica a penetração, que estão intimamente ligadas com sua porosidade total e porosidade de aeração. A densidade do solo é considerada um atributo avaliador da qualidade estrutural do solo utilizada como indicadora de sua estrutura e dureza. Desta forma, alterações dos seus valores refletem em modificações da estrutura do solo, devido à relação que existe entre a densidade e a porosidade total. A resistência a penetração, fisicamente estabelecida pela pressão, é a razão qualquer entre força necessária para a penetração de uma base metálica do penetrômetro, provida de uma extremidade, cuja área basal á conhecida e constante (Montanari et al., 2011).

A geoestatística é uma ferramenta para apoiar o desenvolvimento econômico rural, tornando eficiente o manejo da lavoura de forma localizada, através de obtenção de mapas das áreas e co- letas de amostras previamente planejadas no tempo/espaço. O mapeamento das correlações existentes, diretas ou indiretas entre os atributos do solo e a produtividade das culturas pode ser o diferencial para a decisão de aplicação de taxas variadas de adubos ou descompactação do solo, reduzindo o custo da cultura (Montanari et al., 2005).

Diante do exposto, a presente pesquisa, realizada num Latossolo Vermelho Distroférrico sob sistema plantio direto, na Fazenda de Ensino e Pesquisa da Faculdade de Engenharia de Ilha Solteira (FEIS/UNESP), município de Selvíria (MS), objetivou: a) analisar a variabilidade dos atributos estudados da planta e do solo; b) definir as correlações lineares e espaciais entre a produtividade da massa seca da consorciação de forragens com os atributos físicos do solo pesquisado, e c) pesquisar, entre os atributos físicos estudados do solo, aquele que meIhor se apresente para explicar a variabilidade da produtividade da massa seca da consorciação de forragens.

\section{MATERIAL E MÉTODOS}

O experimento foi conduzido entre novembro de 2006 e fevereiro de 2007, na Fazenda de Ensino e Pesquisa da Faculdade de Engenharia de Ilha Solteira (FEIS/UNESP), município de Selvíria (MS) Mato Grosso do Sul, Brasil. Situado entre as latitudes $20^{\circ} 18^{\prime} 05^{\prime \prime} \mathrm{S}$ e $20^{\circ} 18^{\prime} 28^{\prime \prime} \mathrm{S}$ e as longitudes $52^{\circ} 39^{\prime} 02^{\prime \prime} \mathrm{W}$ e $52^{\circ} 40^{\prime} 28^{\prime \prime} \mathrm{W}$, com precipitação média anual de $1300 \mathrm{~mm}$ e a temperatura média anual $23,7^{\circ} \mathrm{C}$. O tipo climático é Aw, segundo Koeppen, caracterizado como tropical úmido com estação chuvosa no verão e seca no inverno. O solo estudado foi um LATOSSOLO VERMELHO Distroférrico típico muito argiloso, A moderado, hipodistrófico, álico, caulinítico, férrico, epicompactado, muito profundo, moderadamente ácido (EMBRAPA, 2006). Durante o período de condução do experimento a precipitação na região foi de $864,8 \mathrm{~mm}$, a temperatura média foi de $26,1^{\circ} \mathrm{C}$ e a umidade relativa média, de 80,9\% (UNESP, 2008).

Foram definidas as direções dos eixos cartesianos da malha de dados numa área sob pivô central, estabelecida entre dois terraços. Assim, o eixo $x$ foi ordenado em nível e o eixo $y$ ficou no sentido do declive. Deste modo a malha ficou constituída de 117 pontos amostrais, distribuídos numa área de $1600 \mathrm{~m}^{2}(40 \mathrm{~m} \times 40 \mathrm{~m})$. O espaçamento utilizado entre os pontos na grande malha foi de $5 \mathrm{~m}$ enquanto que na malha de refinamento, foi de $1,67 \mathrm{~m}$. Essa última foi locada com a finalidade de se detectar alcances da dependência espacial para espaçamentos menores do que $5 \mathrm{~m}$.

A consorciação realizada foi com plantas de guandu (Cajanus cajan) e milheto (Pennisetum glaucum) com a finalidade de produção de palha. Sua semeadura foi realizada sucedendo a do feijão, no dia 22 de novembro de 2006, em área sob o sistema plantio direto há 15 anos. A semeadura foi efetuada em linhas simples com espaçamento de $0,16 \mathrm{~m}$ entre as culturas, com regulagem da densidade de semeadura de 15 sementes de guandu por metro de linha. 
Para o atributo da planta, a colheita manual foi realizada no dia 5 de fevereiro de 2007 (77 dias após semeadura), determinando-se a área útil de $0,4096 \mathrm{~m}^{2}(0,64 \times 0,64 \mathrm{~m})$ por ponto, com locação do ponto da malha centralizado entre quatro linhas de cultivo, sendo esta metodologia baseada na menor distância entre dois pontos $(1,67 \mathrm{~m})$. Todas as plantas da área útil de cada ponto amostral (PA) foram retiradas por meio de corte com cutelo, aproximadamente de 5 a $7 \mathrm{~cm}$ ao nível do solo, efetuando-se a pesagem para conhecimento da massa úmida total (MU). Posteriormente, para obtenção dos valores da massa seca da forragem (MSF), utilizou-se um fator de correção (FC), o qual representou a relação massa seca/verde para cada ponto amostral, sendo obtido da seguinte forma: foram trituradas 5 plantas de guandu e 5 plantas de milheto escolhidas aleatoriamente dentre todas as plantas coletadas na área útil do ponto amostral. Assim, retirou-se uma pequena amostra a qual foi pesada imediatamente (massa verde). Posteriormente, o material foi devidamente acondicionado em sacos de papel e levado para estufa com circulação forçada de ar à temperatura de $65^{\circ} \mathrm{C}$ por 72 horas até atingir massa constante, sendo pesada novamente (massa seca). Portanto, a expressão para o cálculo do atributo trabalhado da planta, (MSF), individualmente para cada ponto amostral, foi dada por:

MSF= (MU/PA).FC. $10^{4}$

onde: MSF representou a produtividade da massa seca da forragem num determinado ponto amostral $(\mathrm{kg} / \mathrm{ha})$; $\mathbf{M U}$ representou a massa úmida total das plantas contidas na área designada por tal ponto $(\mathrm{kg})$; PA representou a área útil do ponto amostral $\left(\mathrm{m}^{2}\right)$; FC representou o fator de correção da produtividade de massa verde para a produtividade de massa seca da forragem contida no ponto e $10^{4}$ foi o fator de conversão de $\mathrm{kg} / \mathrm{m}^{2}$ para $\mathrm{kg} / \mathrm{ha}$.

As análises laboratoriais foram realizadas no laboratório do Departamento de Fitossanidade, Engenharia Rural e Solos da Faculdade de llha Solteira (UNESP). Os atributos do solo retirados durante o dia 5 de março de 2007, ao redor do ponto amostral, foram: umidade gravimétrica (UG), umidade volumétrica (UV) e resistência à penetração (RP) nas profundidades de 0,00-0,10 m; 0,10-0,20 $\mathrm{m} ; 0,20-0,30 \mathrm{~m}$ e durante os dias 24 a 29 de março de 2007, a densidade do solo (DS) nas mesmas profundidades. A metodologia empregada para a determinação dos atributos físicos do solo foi aquela preconizada pela EMBRAPA (1997). Com o uso de um trado de caneca foram retiradas amostras deformadas de solo para determinar a umidade gravimétrica (UG), relacionada em $[\mathrm{kg} / \mathrm{kg}]$. A densidade do solo (DS) foi determinada pelo método do anel volumétrico, relacionada em $\left[\mathrm{kg} / \mathrm{dm}^{3}\right]$. A resistência a penetração (RP) foi obtida com penetrômetro de impacto, modelo IAA/Planalsucar/Stolf. Os perfis de resistência à penetração foram avaliados para as três profundidades já citadas e a expressão utilizada para o cálculo, determinada por Stolf (1991), foi a mesma utilizada por Santos et al. (2005) e Carvalho et al.(2006), relacionando os va-
GIOIA, M.T. et al. Consorciação de forragens...

lores em [MPa]. A umidade volumétrica foi calculada pela seguinte equação:

UV=UG.DS.

onde: UV é a umidade volumétrica $\mathrm{m}^{3} / \mathrm{m}^{3}$, UG é a umidade gravimétrica $\mathrm{kg} / \mathrm{kg}$ e DS é a densidade do solo $\mathrm{kg} / \mathrm{dm}^{3}$. Dessa forma, a relação dos 12 atributos do solo estudados foi: DS1, DS2, DS3, UG1, UG2, UG3, UV1, UV2, UV3, RP1, RP2 e RP3.

A análise descritiva inicial, matriz de correlação e a análise de regressão entre os atributos estudados foram efetuadas com o SAS (SCHLOTZHAVER e LITTLEL, 1997). A análise geoestatística foi realizada com o uso do Gamma Design Software $7.0\left(\mathrm{GS}^{+}, 2004\right)$. Os ajustes dos semivariogramas simples e cruzados, em função de seus modelos, foram efetuados preferencialmente pela seleção do menor valor da soma dos quadrados dos desvios. A decisão final dos modelos a serem utilizados foi realizada pela análise da validação cruzada levando em conta o valor do coeficiente de correlação e o valor do $b$ da equação. A análise da dependência espacial (ADE) foi efetuada conforme a mesma expressão contida em Kitamura et al. (2007).

\section{RESULTADOS E DISCUSSÃO}

Na Tabela 1 está apresentada a análise descritiva dos atributos estudados. De acordo com Pimentel Gomes e Garcia (2002), a variabilidade de um atributo pode ser classificada segundo a magnitude de seu coeficiente de variação (CV): baixa (CV $\leq 10 \%)$, média $(10 \%<\mathrm{CV} \leq 20 \%)$, alta $(20 \%<\mathrm{CV} \leq$ $30 \%$ ) e muito alta (CV > 30\%). Portanto, a produtividade da massa seca da consorciação de forragens (MSF) apresentou variabilidade muito alta, com um coeficiente de variação de $31,1 \%$, discordando de dados amostrados por Lima (2007) que trabalhou com a massa seca da forragem de milho em um Latossolo Vermelho distroférrico e encontraram variabilidade média com coeficiente de variação de 16,3\%; e também do valor observado por Cavallini et al. (2010) que foi tido como um coeficiente de variação muito alto, de $32,6 \%$, para a matéria seca da forragem de Brachiaria brizantha.

A variabilidade da resistência mecânica à penetração (RP) apresentou-se (Tabela 1) muito alta para RP1, RP2 e RP3, com os valores de 38,2; 30,3 e $30,3 \%$ respectivamente, concordando com Lima (2007) que trabalhando em um Latossolo Vermelho distroférrico encontrou variabilidade muito alta com coeficientes de variação de $32,2 \%$ e $32,4 \%$ para RP1 e RP3 respectivamente, e discordando para RP2 em que a variabilidade encontrada foi tida como baixa. com coeficiente de variação de $9,8 \%$. Souza et al. (2004) quando estudaram esse atributo em um Latossolo Vermelho distrófico sob cultivo de cana-de-açúcar observaram também valores de coeficientes de variação muito altos, sendo de 38,0 ; 37,7 e $36,0 \%$ para as profundidades, $0-0,15 ; 0,15$ 0,30 e $0,30-0,45 \mathrm{~m}$. 
GIOIA, M.T. et al. Consorciação de forragens...

TABELA 1: Análise descritiva inicial da produtividade da massa seca da consorciação de forragens e de al-

\begin{tabular}{|c|c|c|c|c|c|c|c|c|c|c|}
\hline \multirow{3}{*}{ Atributo ${ }^{\text {(a) }}$} & \multicolumn{10}{|c|}{ Medidas estatísticas descritivas } \\
\hline & \multirow[b]{2}{*}{ Média } & \multirow{2}{*}{ Mediana } & \multicolumn{2}{|c|}{ Valor } & \multirow{2}{*}{$\begin{array}{l}\text { Desvio } \\
\text { Padrão }\end{array}$} & \multicolumn{3}{|c|}{ Coeficiente } & \multicolumn{2}{|c|}{$\begin{array}{c}\text { Probabilidade } \\
\text { do teste }^{(\mathbf{b})}\end{array}$} \\
\hline & & & Mínimo & Máximo & & $\begin{array}{l}\text { Variação } \\
(\%)\end{array}$ & Curtose & Assimetria & $\operatorname{Pr}<w$ & DF \\
\hline \multicolumn{11}{|c|}{ Atributo da planta } \\
\hline MSF (kg ha-1) & 20061 & 19426 & 10069 & 40433 & 6234 & 31,1 & $-0,414$ & $-0,037$ & 0,503 & LN \\
\hline \multicolumn{11}{|c|}{ Densidade do solo } \\
\hline DS1 $\left(\mathrm{kg} \mathrm{dm}^{-3}\right)$ & 1,393 & 1,393 & 1,194 & 1,586 & 0,093 & 6,7 & $-0,678$ & $-0,016$ & 0,194 & NO \\
\hline DS2 $\left(\mathrm{kg} \mathrm{dm}^{-3}\right)$ & 1,427 & 1,436 & 1,245 & 1,624 & 0,079 & 5,5 & $-0,173$ & $-0,070$ & 0,673 & NO \\
\hline DS3 $\left(\mathrm{kg} \mathrm{dm}^{-3}\right)$ & 1,438 & 1,444 & 1,295 & 1,553 & 0,060 & 4,2 & $-0,246$ & $-0,479$ & 0,012 & TN \\
\hline \multicolumn{11}{|c|}{ Umidade gravimétrica } \\
\hline UG1 (kg kg $\left.{ }^{-1}\right)$ & 0,163 & 0,162 & 0,092 & 0,210 & 0,020 & 12,3 & $-0,588$ & $-0,027$ & 0,242 & NO \\
\hline UG2 (kg kg $\left.{ }^{-1}\right)$ & 0,180 & 0,180 & 0,139 & 0,232 & 0,018 & 10,0 & $-0,210$ & 0,269 & 0,667 & NO \\
\hline UG3 (kg kg $\left.{ }^{-1}\right)$ & 0,195 & 0,194 & 0,153 & 0,232 & 0,016 & 8,4 & $-0,326$ & 0,221 & 0,630 & NO \\
\hline \multicolumn{11}{|c|}{ Umidade volumétrica } \\
\hline UV1 $\left(\mathrm{m}^{3} \mathrm{~m}^{-3}\right)$ & 0,230 & 0,223 & 0,132 & 0,370 & 0,040 & 17,4 & 0,579 & 0,154 & 0,496 & LN \\
\hline UV2 $\left(\mathrm{m}^{3} \mathrm{~m}^{-3}\right)$ & 0,257 & 0,256 & 0,192 & 0,330 & 0,029 & 11,4 & $-0,444$ & 0,058 & 0,829 & NO \\
\hline UV3 $\left(m^{3} m^{-3}\right)$ & 0,280 & 0,284 & 0,199 & 0,330 & 0,026 & 9,2 & 0,021 & $-0,361$ & 0,251 & NO \\
\hline \multicolumn{11}{|c|}{ Resistência à penetração } \\
\hline RP1 (MPa) & 4,628 & 4,306 & 1,599 & 10,196 & 1,770 & 38,2 & $-0,318$ & $-0,318$ & 0,210 & LN \\
\hline RP2 (MPa) & 4,492 & 4,482 & 2,181 & 9,044 & 1,359 & 30,3 & $-0,715$ & 0,031 & 0,171 & LN \\
\hline RP3 (MPa) & 3,948 & 3,672 & 2,217 & 8,180 & 1,196 & 30,3 & $-0,011$ & 0,444 & 0,047 & LN \\
\hline
\end{tabular}

(a) MSF = produtividade da massa seca da consorciação de forragens; DS, UG, UV e RP, de 1 a 3 , são respectivamente a densidade do solo, umidade gravimétrica, umidade volumétrica e a resistência à penetração do solo; ${ }^{(b)}$ DF = distribuição de frequência, sendo NO, LN e TN respectivamente do tipo normal, lognormal e tendendo à normal

Porém, os valores tidos como muito alta da variabilidade encontrados no presente estudo para a resistência à penetração concordam com os encontrados por Cavallini et al. (2010) que observaram quando estudaram a resistência à penetração num Latossolo sob pastagem valores de variabilidade variando entre alta a muito alta, com valores de 35,$7 ; 24,3$ e $40,7 \%$ nas profundidades de 0,00-0,10; 0,10-0,20 e 0,20-0,30 m, respectivamente.

Os atributos da umidade gravimétrica (UG) e umidade volumétrica (UV) apresentaram variabilidade média nas profundidades $0,00-0,10$ e 0,10 0,20 m com coeficientes de variação de 12,$3 ; 10,0 \%$ para UG e 17,$4 ; 11,4 \%$ para UV. Já na profundidade de $0,20-0,30 \mathrm{~m}$ a variabilidade foi tida como baixa com coeficientes de variação de 8,4 e 9,2 \% para UG e UV, respectivamente, discordando de Lima (2007) que encontrou variabilidade alta para UG na camada de 0,00-0,10 m com coeficiente de variação de $21,7 \%$ e concordando para a camada de 0,10 $0,20 \mathrm{~m}$ com variabilidade média apresentando um coeficiente de variação de $13,1 \%$. Concordou também com Lima (2007) para a umidade gravimétrica na camada de 0,20-0,30 m mostrando baixa variabilidade com coeficiente de variação de $8,8 \%$. Já Rosa Filho (2008) trabalhando com duas profundidades $(0,00-0,10$ e $0,10-0,20 \mathrm{~m})$ encontrou variabilidade baixa para o atributo umidade volumétrica na primeira e segunda camada (UV1 e UV2) com coeficiente de variação de 6,1 e 4,5\% respectivamente, discordando dos dados encontrado no presente trabalho.

Em relação aos valores encontrados para a densidade do solo (DS1, DS2 e DS3) esses apresentaram variabilidade baixa com coeficientes de variação de 6,$7 ; 5,5$ e 4,2\% respectivamente, sendo que, assemelham-se com dados os obtidos por Lima (2007) que trabalhou em um Latossolo VermeIho distroférrico sob plantio direto numa malha geoestatística constituída de 125 pontos amostrais e encontrou variabilidade baixa para os atributos acima citados, sendo os respectivos valores de 9,8; 3,1 e $4,1 \%$. Montanari et al. (2008) também encontraram variabilidade baixa para a densidade do solo nas profundidades $0,00-0,10,0,10-0,20 ; 0,20-0,30 \mathrm{e}$ 0,30-0,40 m em um Latossolo Vermelho distroférri- 
co sob plantio direto em uma rede de $165 \times 60 \mathrm{~m}$ com coeficientes de variação entre 4,1 a 5,6 \%. Cavallini et al. (2010) também encontraram baixa variabilidade para a densidade do solo nas três camadas de solo estudas sendo os valores de 6,6; 4,1 e $4,0 \%$.

Quando uma variável qualquer possui distribuição de freqüência do tipo normal, a medida de tendência central mais adequada para representá-la deve ser a média. Por outro lado, para variáveis com distribuição lognormal deve-se usar a mediana. Assim, para os atributos apresentados no Quadro 1, a distribuição de freqüência foi do tipo normal para a DS1, DS2, UG1, UG2, UG3, UV2 e UV3, com coeficientes de assimetria positiva entre 0,058 e 0,269 , assim como negativa entre $-0,361$ e $-0,016$. O coeficiente de curtose positiva foi de 0,021 , assim como negativas entre $-0,678$ e $-0,173$. Para os atributos MSF, UV1, RP1, RP2 e RP3 que apresentaram distribuição de freqüência do tipo lognormal, os coeficientes de assimetria positiva foram entre 0,031 e 0,444 , assim como negativa de $-0,318$ e os coeficientes de curtose todos positivos variando entre 0,047 e 0,496 . Para DS3 a distribuição foi tendendo a normal com coeficiente de assimetria negativa de $-0,479$ e coeficiente de curtose com valor de $-0,246$.

Quadro 1 Matriz de correlaçăo linear simples entre a produtividade de massa seca da consorciaçăo de forragens e algans atributos fisicos de um Latossolo Vermelho Distroférico de Selviria (MS)

\begin{tabular}{|c|c|c|c|c|c|c|c|c|c|c|c|c|}
\hline \multirow{2}{*}{ Atributos ${ }^{(2)}$} & \multicolumn{12}{|c|}{ Coeficiente de correlaçào } \\
\hline & MSF & DS1 & DS2 & DS3 & UG1 & UG2 & UG3 & UV1 & UV2 & UV3 & RP1 & RP2 \\
\hline DS1 & 0,071 & & & & & & & & & & & \\
\hline DS2 & $=0,088$ & $0,243^{* *}$ & & & & & & & & & & \\
\hline DS3 & $-0,062$ & 0,133 & $0,462^{*}$ & & & & & & & & & \\
\hline UG1 & $-0,005$ & $0,256^{*}$ & 0,000 & $-0,069$ & & & & & & & & \\
\hline UG2 & $-0,013$ & $0,267^{* *}$ & 0,014 & $-0,024$ & $0,787^{*+}$ & & & & & & & \\
\hline UG3 & $-0,139$ & $0,276^{*}$ & 0,095 & $-0,037$ & $0,658^{* *}$ & $0,782^{* *}$ & & & & & & \\
\hline UV1 & 0,018 & $0,571^{* *}$ & 0,107 & 0,031 & $0,813^{* *}$ & $0,726^{* *}$ & $0,616^{*}$ & & & & & \\
\hline UV2 & $-0,064$ & $0,341^{* *}$ & $0,486^{*}$ & $0,199^{*}$ & $0,683^{* *}$ & $0,879^{* *}$ & $0,731^{*}$ & $0,679^{* *}$ & & & & \\
\hline UV3 & $=0,165$ & $0,314^{* *}$ & $0,298^{*}$ & $0,419^{* *}$ & $0,567^{*+}$ & $0,700^{* *}$ & $0,891^{* *}$ & $0,577^{*}$ & $0,756^{*}$ & & & \\
\hline RP1 & $0,217^{*}$ & $-0,047$ & 0,061 & 0,121 & $-0,371^{* *}$ & $-0,321^{*}$ & $-0,352^{* *}$ & $-0,243^{*-1}$ & $-0,257^{\prime \prime}$ & $-0,269^{*}$ & & \\
\hline RP2 & 0,088 & $-0,020$ & $-0,050$ & 0,098 & $-0,340^{* *}$ & $-0,383^{n}$ & $-0,417^{* *}$ & $-0,202^{*}$ & $-0,361^{*}$ & $-0,337^{* *}$ & $0,612^{* *}$ & \\
\hline RP3 & 0,018 & $-0,068$ & $-0,080$ & 0,062 & $-0,331^{* *}$ & $-0,375^{\prime \prime}$ & $-0,482^{* *}$ & $-0,204^{*}$ & $-0,362^{* *}$ & $-0,408^{* *}$ & $0,525^{*}$ & $0,742^{* *}$ \\
\hline
\end{tabular}

- Miprémasicativo a $5 \%$

Quando uma variável qualquer possui distribuição de freqüência do tipo normal, a medida de tendência central mais adequada para representá-la deve ser a média. Por outro lado, para variáveis com distribuição lognormal deve-se usar a mediana. Assim, para os atributos apresentados no Quadro 1, a distribuição de freqüência foi do tipo normal para a DS1, DS2, UG1, UG2, UG3, UV2 e UV3, com coeficientes de assimetria positiva entre 0,058 e 0,269 , assim como negativa entre $-0,361$ e $-0,016$. O coeficiente de curtose positiva foi de 0,021 , assim como negativas entre $-0,678$ e $-0,173$. Para os atributos MSF, UV1, RP1, RP2 e RP3 que apresentaram distribuição de freqüência do tipo lognormal, os coeficientes de assimetria positiva foram entre 0,031 e 0,444 , assim como negativa de $-0,318$ e os coeficientes de curtose todos positivos variando entre 0,047 e 0,496 . Para DS3 a distribuição foi tendendo a normal com coeficiente de assimetria negativa de $-0,479$ e coeficiente de curtose com valor de $-0,246$.

Dessa forma, a distribuição de freqüência do tipo normal, obtida para a maioria dos atributos estudados ficou de acordo com os seguintes auto- res, classificados conforme o atributo: DS; Santos et al. (2006) trabalhando em um Latossolo VermeIho distroférrico sob plantio direto, UG; Freddi et al. (2006) trabalhando em um Latossolo Vermelho sob preparo convencional e UV; Marins (2006) trabaIhando em um Latossolo cultivado com soja. A distribuição de freqüência do tipo lognormal discordou de Lima et al. (2007) para o atributo massa seca da forragem (MSF) que trabalharam em um Latossolo Vermelho distrófico encontraram distribuição normal para o atributo em milho. Já para a resistência mecânica a penetração a distribuição de freqüência apresentou-se do tipo lognormal para todas as profundidades concordando com Santos et al. (2005) que trabalharam em um mesmo solo analisando a produtividade de grãos de feijão. Resultados obtidos por Rosa Filho (2008) discordam com a distribuição lognormal para a umidade volumétrica, pois em amostragem realizada em um Latossolo VermeIho distroférrico sob plantio direto encontrou distribuição normal. E a distribuição de freqüência tendendo a normal discorda com Lima (2007) para densidade na camada de $0,20-0,30 \mathrm{~m}$ onde trabaIhando em um Latossolo Vermelho distrófico encon- 
trou uma distribuição normal para os esses dados. Maior Junior (2006) estudando arranjos populacionais de feijão guandu em região semiárida, sob Luvissolo Crômico Órtico, obteve a produtividade da massa seca média de $1790 \mathrm{~kg} / \mathrm{ha}$ e Pires et al. (2007) trabalhando com cultivares de milheto em um Latossolo Vermelho distrófico encontraram uma produtividade média de até 19690 $\mathrm{kg} / \mathrm{ha}$ da massa seca da forragem. O valor da mediana para massa seca da forragem foi $19426 \mathrm{~kg} / \mathrm{ha}$ na consorciação ficou com valores próximos da média de produtividade do milheto isoladamente e acima da produção de guandu (Tabela 1).

Os valores médios para os atributos do solo estudados estão apresentados na Tabela $1 \mathrm{e}$ foram: 1,$393 ; 1,427$ e $1,438 \mathrm{~kg} / \mathrm{dm}^{3}$ para densidade do solo nas profundidades de $0-0,10 ; 0,10-0,20$ e $0,20-0,30 \mathrm{~m}$, respectivamente. Oliveira e Moniz (1975) efetuaram o levantamento pedológico detaIhado dos solos da Estação Experimental do Instituto Agronômico do Estado de São Paulo, localizada em Ribeirão Preto. Dessa forma, foram relatados, para um Latossolo Vermelho distroférrico e nas condições de solo virgem sob mata natural, valores da densidade do solo originados da secção de controle do perfil do solo, respectivamente entre 0,98 e $1,13 \mathrm{~kg} / \mathrm{dm}^{3}$. Portanto, com base nessa caracterização, para a densidade do solo, os valores médios de densidade do solo apresentaram uma magnitude que indicou a presença de compactação do solo nas camadas estudadas. Tal compactação, no sistema plantio direto é originada pelo trânsito das máquinas e implementos agrícolas, assim como ao tempo de adoção deste sistema, sem que, contudo, seja efetuada uma prática conservacionista do solo que venha a reverter esse problema (ASSIS, 2005). Dessa forma, tais resultados ficaram de acordo com aqueles da pesquisa de Secco et al. (2004), que encontraram valores de densidade do solo semelhantes e/ou superiores a $1,45 \mathrm{~kg} / \mathrm{dm}^{3}$, também para um Latossolo Vermelho distroférrico.

Para a umidade gravimétrica as médias foram 0,$163 ; 0,180$ e $0,195 \mathrm{~kg} / \mathrm{kg}$ para as profundidades $0-0,10 ; 0,10-0,20$ e $0,20-0,30 \mathrm{~m}$, respectivamente. Bengough et al. (2001) relataram que a condição ideal de umidade do solo, para a coleta dos dados de resistência à penetração, deve ser quando ela estiver variando entre a capacidade de campo e até com um terço a menos de água, isto é, quando o solo ideal, conceituado por Kiehl (1979), apresentar uma umidade volumétrica na microporosidade variando entre 0,33 e $0,22 \mathrm{~m}^{3} / \mathrm{m}^{3}$. Portanto, uma vez que a capacidade de campo do solo em questão, determinada por Martins (2007), foi de $0,351 \mathrm{~m}^{3} / \mathrm{m}^{3}$, deve-se salientar que os dados da presente pesquisa foram coletados em ótimas condições de umidade volumétrica do solo $(0,230$; 0,257 e $0,280 \mathrm{~m}^{3} / \mathrm{m}^{3}$ para as profundidades $0-0,10$; $0,10-0,20$ e $0,20-0,30 \mathrm{~m}$, respectivamente) (Tabela 1), uma vez que os valores de resistência mecânica a penetração foram: 4,628; 4,492 e 3,948 MPa para as profundidades $0-0,10 ; 0,10-0,20$ e $0,20-0,30 \mathrm{~m}$, respectivamente. Por outro lado, quando utilizada a classificação de Arshad et al. (1996), os altos valores da resistência à penetração do solo corroboraram para classificar o solo como compactado, de forma a suscitar que a produtividade de massa seca da forragem pôde também não ter atingido seu máximo potencial, uma vez que pôde ter ocorrido um alto impedimento mecânico ao desenvolvimento de suas raízes. No entanto, como já discutido, o valor da produtividade de massa seca da forragem foi satisfatório para a região estudada já que as duas espécies estudadas têm sistema radicular agressivo e toleram estresse hídrico.

$\mathrm{Na}$ Tabela 2 está apresentada a matriz de correlação linear simples entre o atributo produtividade da massa seca da consorciação das forragens (MSF) e os atributos do solo (DS, UG, UV e RP).

A correlação entre a produtividade da massa seca da forragem (MSF) e os atributos do solo (Tabela 2) apresentou significância exclusiva para o par: MSF x RP1 $\left(r=0,217^{*}\right)$. Uma das possíveis explicações para esse acontecimento advém da época em que a consorciação da forragem foi semeada, época com boa disponibilidade hídrica e em caso de ter ocorrido algum veranico essas espécies respondem bem a períodos de estiagem. Outra hipótese que corrobora com tal resultado é o fato que o aumento da resistência mecânica a penetração evidenciar o aumento na densidade do solo e conseqüentemente o aumento dos microporos assim aumentar a retenção/disponibilidade de água. Esse adensamento superficial comum em lavouras sob plantio direto (Montanari et al., 2010) aumenta o contato do solo com a raiz facilitando a absorção de água e nutrientes, e provavelmente, o adubo residual da cultura anterior (Kiehl 1985; Arf et al., 1999).

A exclusiva equação de regressão linear simples entre os atributos pesquisados, no âmbito das correlações estabelecidas entre planta versus solo, está apresentada na Figura 1. No âmbito da correlação entre atributos da planta versus solo, o modelo matemático $M S F=f(R P 1)$, representado na Figura 1, apresentou uma relação linear crescente e coeficiente de determinação de $0,047^{*}$. Estudo feito por Cavallini et al. (2010) numa rede geoestatística de 124 pontos num Latossolo sob pastagem de braquiária não encontraram uma relação linear crescente significativa entre MSF e RP1, e sim uma relação linear decrescente não significativa (MSF $x$ $\left.\mathrm{RP} 1=-0,105^{\mathrm{ns}}\right)$.

$\mathrm{Na}$ Tabela 3 estão apresentados os parâmetros dos semivariogramas simples ajustados para a produtividade da massa seca da consorciação de forragens e alguns atributos físicos de um Latossolo Vermelho distroférrico de Selvíria (MS). No tocante ao desempenho dos semivariogramas a relação decrescente deles, analisada pela grandeza do coeficiente de determinação espacial $\left(r^{2}\right)$, foi a seguinte: 1) 0,972 (UV1); 2) 0,969 (UG3); 3) 0,962 (UG1); 4) 0,945 (UG2); 5) 0,929 (UV2); 6) 0,927 (DS3); 7) 0,925 (DS2); 8) 0,904 (DS1); 9) 0,891 (MSF) e 10) 0,800 (RP3). 
Observa-se que, para todos os atributos ajustados, os valores dos coeficientes de determinação espacial apresentaram elevados. Para os oito primeiros com valores de $r^{2}$ variando entre 0,972 e 0,904 constata-se uma correlação espacial alta para a umidade (UG e UV) e a densidade (DS) indicando que estes atributos possuem um melhor ajuste semivariográfico. Para os valores de umidade gravimétrica nos três níveis estudados estão de acordo com o valores obtido por Santos et al.(2005) com coeficientes de determinação espacial variando entre 0,974 e 0,946. Em relação ao $A D E$, o alto valor observado para a umidade gravimétrica, UG1, $88,3 \%$ e UG2, $80,9 \%$ também esta semelhante ao referido autor, com valores de $75,5 \%$ e $86,6 \%$, respectivamente. Já para a profundidade de 0,20$0,30 \mathrm{~m}$ o dado da avaliação de dependência espacial (ADE) foi moderado $(50,1 \%)$ discordando com o autor citado que encontrou valor forte de $79,5 \%$.

O modelo ajustado para a umidade gravimétrica do solo foi gaussiano para UG1 e UG3 discordando de Souza et al. (2006) que trabalhando com um Latossolo Vermelho Distrófico sob cana-deaçúcar encontrou modelo esférico para essas profundidades em duas épocas diferentes. Já Santos et al. (2005) encontraram modelo exponencial para o segundo nível de acordo com dados obtidos. No âmbito da densidade do solo, os coeficientes de determinação espacial variaram entre 0,$927 ; 0,925$ e 0,904 , com ADE moderado, forte e forte para as profundidades estudadas. Sobre o ADE, os valores encontrados foram de $57,3 \%, 82,0$ e 88,3 com modelos matemáticos tipo gaussiano para DS1, DS2 e DS3, respectivamente. Na Tabela 3 , a relação decrescente dos alcances foi a seguinte: 1) 13,3 (UV2); 2) 11,5 (DS3); 3) 11,0 (UG1); 4) 9,9 (DS1); 5) 9,6 (MSF); 6) 8,4 (DS2); 7) 7,8 (UG2); 8) 7,6 (UV1);
9) 7,36 (RP3) e 10) 6,7 (UG3). Portanto, nas condições da presente pesquisa, assim como, visando auxiliar pesquisas futuras, na qual os mesmos atributos estejam envolvidos, os valores dos alcances a serem utilizados nos pacotes geoestatísticos, que alimentarão os pacotes computacionais empregados na agricultura de precisão, no geral, não deverão ser menores do que 6,7. Por outro lado, exclusivamente para 0 atributo produtividade da massa seca da consorciação de forragens os alcances não deverão ser menores do que 9,6 m, sob sistema de plantio direto.

Na Figura 2 estão apresentados o semivariograma cruzado, a validação cruzada e o mapa de co-krigagem da densidade do solo em função da umidade gravimétrica de um Latossolo Vermelho distroférrico de Selvíria (MS). Assim, entre os atributos estudados a densidade do solo e a umidade gravimétrica, foram os únicos atributos com dependência espacial entre eles, indicando como já visto que, a umidade do solo é um indicador da qualidade física do solo.

\section{CONCLUSÕES}

No âmbito da correlação linear, o atributo que melhor explica a produtividade da massa seca da consorciação foi a resistência a penetração no nível de 0,00- 0,10 m, com uma correlação linear positiva.

A umidade volumétrica e a densidade do solo foram os atributos que mais se relacionaram para estimar a qualidade física do solo.

Não houve correlação espacial entre os atributos físicos do solo estudados com a produtividade da massa seca da consorciação (guandu+milheto) sob sistema de plantio direto.

\section{REFERÊNCIAS}

1.ANDREOTTI, M.; ARALDI, M.; GUIMARÃES, V. F.; FURLANI, E.; BUZETTI, S. Winter corn yield and chemical modifications in latosol as a function of covering species after lime application under no-tillage system. Acta Scientiarum. v. 30, n. 1, p.109$115,2008$.

2.ARF, O.; SILVA, L. S.; BUZETTI, S.; ALVES, M. C.; SÁ. M. E.; RODRIGUES, R. A. F.; HERNANDEZ, F. B. T. Efeito da rotação de culturas, adubação verde e nitrogenada sobre o rendimento do feijão. Pesquisa Agropecuária Brasileira, Brasília, v.34, n.11, p.2029-2036, 1999.

3.ARSHAD, M. A.; LOWERY, B.; GROSSMAN, B. Physical tests for monitoring soil quality. In: DORAN, J. W.; A .J.; (Eds). Methods for assessing soil quality. Madison: Soil Science Society of America, p.123-141, 1996. (SSSA Special publication, 49).

4.ASSIS, J. A. Estratégias de monitoramento da compreensão no gênero textual e-mai. Scripta, Belo Horizonte: Editora da PUC Minas, v. 8, n. 16, p. 100-108, 2005

5.BENGOUGH, A. G.; CAMPBELL, D. J.; O' SULLIVAN, M. F. Penetrometer Techniques in relation to Soil Compaction and Root Growth. In: Soil and Environmental Analysis: Physical Methods. 2 ed. Marcel Dekker, Inc. p.377-403, 2001.

6.CARVALHO, G. J., CARVALHO, M. P.; FREDDI, O. S.; MARTINS, M. V. Correlação da produtividade do feijão com a resistência à penetração do solo sob plantio direto. R. Bras. Eng. Agr. Amb., v.10, p.765-771, 2006.

7.CAVALLINI, M. C; ANDREOTTI M.; OLIVEIRA L. L.; PARIZ C. M.; CARVALHO M. P. Relações entre produtividade de Brachiaria Brizantha e atributos físicos de um latossolo do cerrado. Rev. Bras. Ciênc. Solo, v.34, n.4, p.1007-1015, 2010.

8.EMPRESA BRASILEIRA DE PESQUISA AGROPECUÁRIA - EMBRAPA. Manual de métodos de análises de solo. 2.ed. Rio de Janeiro, Ministério da Agricultura e do Abastecimento, 212p., 1997.

9.EMPRESA BRASILEIRA DE PESQUISA AGROPECUÁRIA - EMBRAPA. Centro Nacional de Pesquisa de Solos. Sistema brasileiro de classificação de solos. 2.ed. Rio de Janeiro, 2006. 306p.

10.FREDDI, O. S.; CARVALHO, M. P.; VERONESI JÚNIOR, V. e CARVALHO, G. J. Produtividade do milho relacionada com a resistência mecânica à penetração do solo sob preparo convencional. Eng. Agríc., v.26, p.113-121, 2006.

11.GS+: Geostatistics for environmental sciences. 7. ed. Michigan, Plainwell: Gamma Desing Software, 2004. 159p.

12.KIEHL, E. J. Manual de edafologia: relações solo-planta. São Paulo: Agronômica Ceres, 1979. 264p.

13.KIEHL, J. E. Fertilizantes orgânicos. Piracicaba: Agronômica Ceres, 492 p. 1985.

14.KITAMURA, A. E.; CARVALHO, M. P.; LIMA, C. G. R. Relação entre a variabilidade espacial das frações granulométricas do solo e a produtividade do feijoeiro sob plantio direto. Revista Brasileira de Ciência do Solo, Viçosa, MG, v. 31, p.361 -369, 
GIOIA, M.T. et al. Consorciação de forragens...

TABELA 3: Parâmetros dos semivariogramas simples ajustados para produtividade da massa seca da consorciação de forragens e alguns atributos físicos de um Latossolo Vermelho distroférrico de Selvíria (MS)

\section{Parâmetros}

\begin{tabular}{|c|c|c|c|c|c|c|c|c|}
\hline \multirow[t]{2}{*}{ Atributo (a) } & \multirow[t]{2}{*}{ Modelo ${ }^{(b)}$} & \multirow{2}{*}{$\begin{array}{c}\text { Efeito } \\
\text { Pepita } \\
\left(C_{0}\right)\end{array}$} & \multirow{2}{*}{$\begin{array}{l}\text { Patamar } \\
\left(\mathrm{C}_{0}+\mathrm{C}\right)\end{array}$} & \multirow{2}{*}{$\begin{array}{c}\text { Alcance } \\
\qquad \begin{array}{c}\left(A_{0}\right) \\
(m)\end{array}\end{array}$} & \multirow{2}{*}{$r^{2}$} & \multirow{2}{*}{$S Q R^{(c)}$} & \multicolumn{2}{|c|}{ Avaliador da dependência espacial } \\
\hline & & & & & & & $\mathrm{ADE}^{(\mathrm{d})}$ & Classe \\
\hline \multicolumn{9}{|c|}{$Y(h)$ simples dos atributos da planta } \\
\hline MSF & gau & $1,401.10^{7}$ & $1,779.10^{7}$ & 9,6 & 0,891 & $2,620.10^{13}$ & 60 & Moderada \\
\hline \multicolumn{9}{|c|}{$Y(h)$ simples dos atributos físicos do solo } \\
\hline $\begin{array}{l}\text { DS1 }\left(\mathrm{kg} \mathrm{dm}^{-3}\right) \\
\text { DS2 }\left(\mathrm{kg} \mathrm{dm}^{-3}\right) \\
\text { DS3 }\left(\mathrm{kg} \mathrm{dm}^{-3}\right) \\
\text { UG1 }\left(\mathrm{kg} \mathrm{kg}^{-1}\right) \\
\text { UG2 }\left(\mathrm{kg} \mathrm{kg}^{-1}\right) \\
\text { UG3 }\left(\mathrm{kg} \mathrm{kg}^{-1}\right) \\
\text { UV1 }\left(\mathrm{m}^{3} \mathrm{~m}^{-3}\right) \\
\text { UV2 }\left(\mathrm{m}^{3} \mathrm{~m}^{-3}\right) \\
\text { UV3 }\left(\mathrm{m}^{3} \mathrm{~m}^{-3}\right) \\
\text { RP1 (MPa) } \\
\text { RP2 (MPa) } \\
\text { RP3 (MPa) }\end{array}$ & $\begin{array}{l}\text { gau } \\
\text { gau } \\
\text { gau } \\
\text { gau } \\
\text { exp } \\
\text { gau } \\
\text { exp } \\
\text { esf } \\
\text { epp } \\
\text { epp } \\
\text { epp } \\
\text { exp }\end{array}$ & $\begin{array}{c}3,297 \cdot 10^{-3} \\
9,700 \cdot 10^{-4} \\
3,740 \cdot 10^{-4} \\
4,000 \cdot 10^{-5} \\
6,100 \cdot 10^{-5} \\
1,110 \cdot 10^{-4} \\
1,480 \cdot 10^{-4} \\
3,870 \cdot 10^{-4} \\
6,020.10^{-9} \\
3,154 \\
1,838 \\
5,250 \cdot 10^{-1}\end{array}$ & $\begin{array}{c}7,721 \cdot 10^{-3} \\
5,400 \cdot 10^{-3} \\
3,188 \cdot 10^{-3} \\
3,510 \cdot 10^{-4} \\
3,180 \cdot 10^{-4} \\
2,370 \cdot 10^{-4} \\
1,166 \cdot 10^{-3} \\
7,750 \cdot 10^{-4} \\
6,020 \cdot 10^{-9} \\
3,154 \\
1,838 \\
1,312\end{array}$ & $\begin{array}{c}9,9 \\
8,4 \\
11,5 \\
11,0 \\
7,8 \\
6,7 \\
7,6 \\
13,3 \\
- \\
- \\
- \\
7,4\end{array}$ & $\begin{array}{c}0,904 \\
0,925 \\
0,927 \\
0,962 \\
0,945 \\
0,969 \\
0,972 \\
0,929 \\
- \\
- \\
- \\
0,800\end{array}$ & $\begin{array}{c}1,293 \cdot 10^{-6} \\
6,990 \cdot 10^{-9} \\
1.725 \cdot 10^{-7} \\
1,081 \cdot 10^{-9} \\
8,958 \cdot 10^{-10} \\
3,524 \cdot 10^{-10} \\
6,502 \cdot 10^{-9} \\
9,286 \cdot 10^{-9} \\
- \\
- \\
- \\
2,050 \cdot 10^{-2}\end{array}$ & $\begin{array}{c}57,3 \\
82,0 \\
88,3 \\
88,3 \\
80,9 \\
50,1 \\
87,3 \\
50,1 \\
- \\
- \\
- \\
60,0\end{array}$ & $\begin{array}{l}\text { Moderada } \\
\text { Forte } \\
\text { Forte } \\
\text { Forte } \\
\text { Forte } \\
\text { Moderada } \\
\text { Forte } \\
\text { Moderada } \\
- \\
- \\
- \\
\text { Moderada }\end{array}$ \\
\hline
\end{tabular}

(a) $\mathrm{MSF}=$ massa seca da forragem, DS = densidade do solo, UG = umidade gravimétrica, UV = umidade volumétrica, RP = resistência mecânica à penetração; ${ }^{(b)}$ gau= gaussiano, exp = exponencial, esf = esférico e epp = efeito pepita puro; ${ }^{(c)} S Q R=$ soma dos quadrados dos resíduos; (d) ADE = avaliador da dependência espacial.

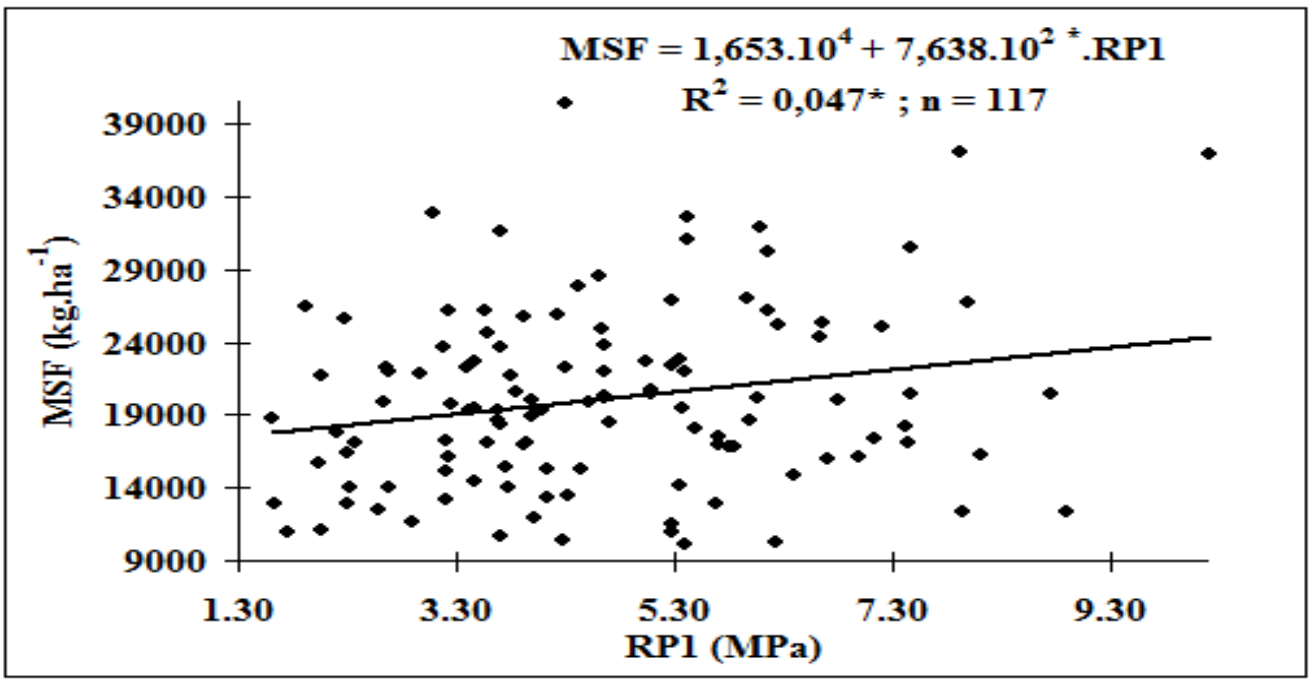

FIGURA 1: Equação de regressão entre a produtividade da massa seca da consorciação de forragens e a resistência à penetração na camada de 0,00-0,10 m de um Latossolo Vermelho distroférrico de Selvíria (MS). 
GIOIA, M.T. et al. Consorciação de forragens...

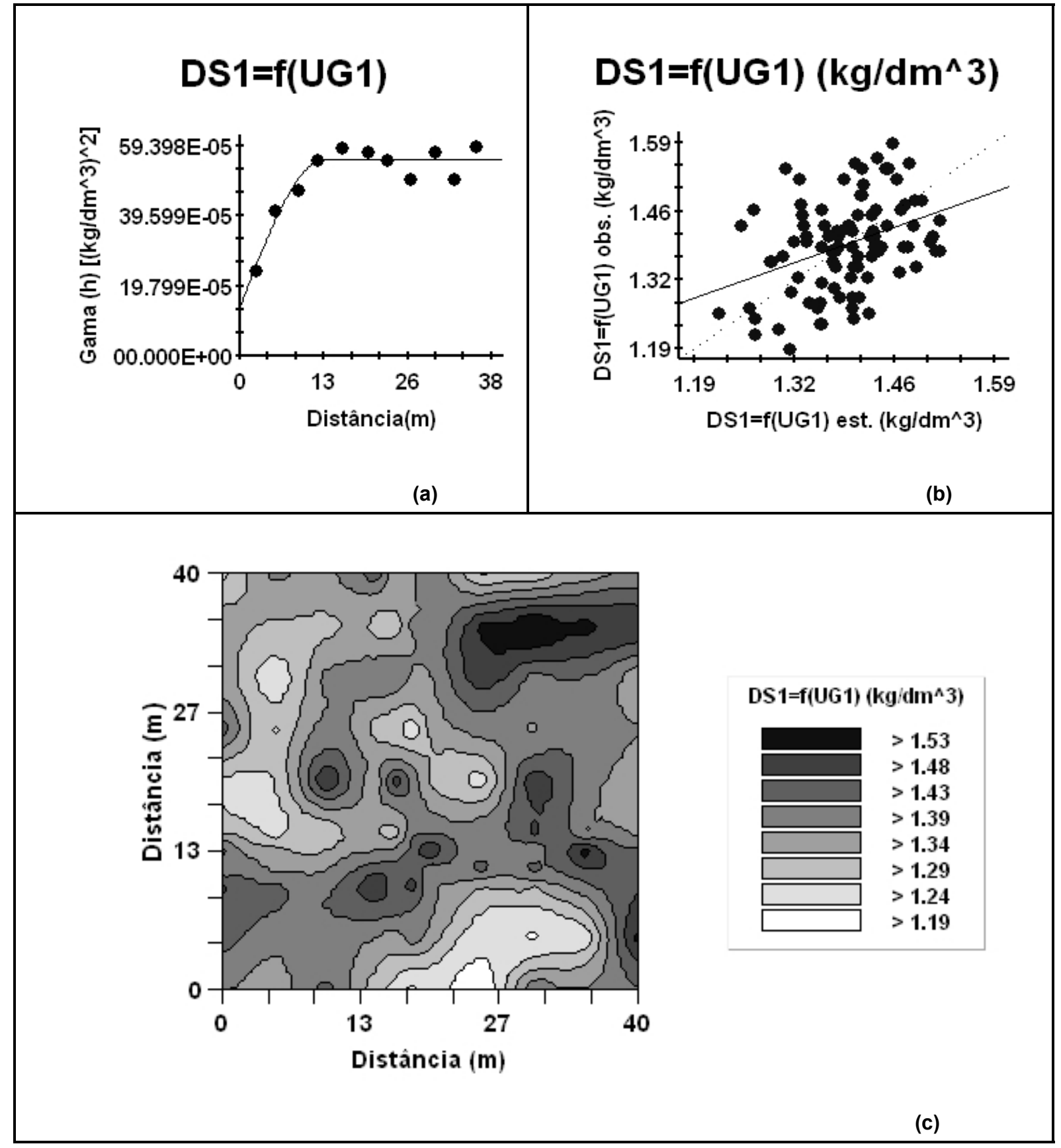

FIGURA 2: Semivariograma cruzado, validação cruzada e mapa de co-krigagem da densidade do solo (DS1) em função da umidade gravimétrica (UG1) de um Latossolo Vermelho Distroférrico de Selvíria (MS). 
GIOIA, M.T. et al. Consorciação de forragens...

1.LIMA, C. G. R. Correlação linear e espacial da produtividade de forragem de milho com atributos físicos de um Latossolo Vermelho Distrófico. Ilha Solteira, 2007, 107p. Dissertação. (Mestrado em Sistemas de Produção) - Faculdade de Engenharia de llha Solteira, Universidade Estadual Paulista, llha Solteira.

2.LIMA, C. G. R; CARVALHO, M. P.; MELLO, L. M. M.; LIMA, R. C. Correlação linear e espacial entre a produtividade de forragem, a porosidade total e densidade do solo de Pereira Barreto (SP). R. Bras. Ci. Solo, v.31, p.1244, 2007.

3.LUPATINI, G. C. Produção animal em milheto (Pennisetum americanum (L.) Leeke) submetido a níveis de adubação nitrogenada. Santa Maria: Universidade Federal de Santa Maria, 1996. 126p. Dissertação (Mestrado em Zootecnia) Universidade Federal de Santa Maria, 1996.

4.MAIOR JÚNIOR, S. G. S. Efeitos de arranjos populacionais na produção de forragem de feijão guandu (Cajanus cajan (L) Millsp.) em região semi-árida. Campina Grande, 2006. 36p. Dissertação: (Mestrado em Zootecnia) - Centro de saúde e Tecnologia Rural, Universidade Federal de Campina Grande.

5.MARINS, A. C. Métodos de estimação da função semivariância aplicados a dados simulados e reais de produtividade da soja e de atributos físicos de um Latossolo. Cascavel, 2006. 140p. Dissertação: (Mestrado em Engenharia agrícola) Centro de Ciências Exatas e Tecnológicas, Universidade Estadual do Oeste do Paraná.

6.MARTINS, M. V. Aspectos lineares e espaciais da correlação entre a produtividade de feijão (Phaseolus vulgaris $L$ ) com atributos físicos do solo. 2007. 28 f. Trabalho de Conclusão de Curso (Agronomia) - Faculdade de Engenharia, Universidade Estadual Paulista, Ilha Solteira, 2007.

7.MONTANARI, R.; MARQUES JÚNIOR, J.; PEREIRA, G. T.; SOUZA, Z. M. Forma da paisagem como critério para otimização amostral de latossolos sob cultivo de cana-de-açúcar. Pesquisa Agropecuária Brasileira, Brasília, DF, v.40, n.1, p.69-77, 2005

8.MONTANARI, R.; PEREIRA, G. T.; MARQUES JÚNIOR, J.; SOUZA, Z. M.; PAZETO, R. J.; CAMARGO, L. A. Variabilidade espacial de atributos químicos em Latossolo e Argissolos. Ciência Rural, Santa Maria, v.38, n.5, p.1266-1272, 2008.

9.MONTANARI, R.; CARVALHO, M. P.; ANDREOTTI, M.; DALCHIAVON, F. C.; LOVERA, L. H.; HONORATO, M. A. O. Aspectos da produtividade do feijão correlacionados com atributos físicos do solo sob elevado nível tecnológico de manejo. Rev. Bras. Ciênc. Solo, Viçosa, v. 34, n. 6, Dec. 2010

10.MONTANARI, R., LIMA. R. C., BONINI, A. S., MARQUES, L. S., MINGUINI, R., CARVALHO, M. P., FERREIRO, J. and COSTA, N. R.Variabilidade dos atributos de um latossolo vermelho sob plantio direto no cerrado brasileiro e produtividade da soja. Cadernos Laboratorio Xeolóxico de Laxe. n. 36, v. 36, p. 61-78, 2011.

11.OLIVEIRA, J. B.; MONIZ, A. C. Levantamento pedológico detalhado da estação experimental de Ribeirão Preto, SP. Revista Bragantia, v.34, p.59-114, 1975.

12.PIMENTEL-GOMES, F.; GARCIA, C. H. Estatística aplicada a experimentos agronômicos e florestais: Exposição com Exemplos e Orientações para Uso de Aplicativos. Piracicaba: FEALQ, 309 p. 2002.

13.PIRES, F. R.; ASSIS, R. L. de; SILVA, G. P.; BRAZ, A. J. B. P.; SANTOS, S. C. G; VIEIRA NETO, S. A.; SOUSA, J. P. G. de. Desempenho agronômico de variedades de milheto em razão da fenologia em pré-safra. Bioscience Journal, Uberlândia, v.23, n.3, p.41-49, 2007

14.ROSA FILHO, G. Produtividade da soja em função de atributos físicos de um Latossolo Vermelho Distroférrico sob plantio direto. Ilha Solteira, 2008. 89f. Dissertação. (Mestrado em Sistemas de Produção) - Faculdade de Engenharia de Ilha Solteira, Universidade Estadual Paulista, llha Solteira, 2008

15.SANTOS, P. A.; CARVALHO, M. P.; FREDDI, O. S.; KITAMURA, A. E.; FREITAS, E. E.; VANZELA, L. S. Correlação linear e espacial entre o rendimento de grãos do feijoeiro e a resistência mecânica à penetração em um Latossolo Vermelho distroférrico. R. Bras. Ci. Solo, v.29, p.287-295, 2005.

16.SANTOS, M. L.; CARVALHO, M. P.; RAPASSI, R. M. A.; MURAISHI, C. T.; MALLER, A. e MATOS, F. A. Correlação linear e espacial entre produtividade de milho (Zea mays L.) e atributos físicos de um Latossolo Vermelho distroférrico sob plantio direto do Cerrado Brasileiro. Acta Sci. Agron., v.28, p.313-321, 2006.

17.SCHLOTZHAVER, S. D. e LITTELL, R. C. SAS System for elementary statistical analysis. 2.ed. Cary, 1997. 905p.

18.SECCO, D.; REINERT, D. J.; REICHERT, J. M.; ROS, C. O. Produtividade de soja e propriedades físicas de um Latossolo submetido a sistemas de manejo e compactação. Revista Brasileira de Ciência do Solo, v.28, p.797-804, 2004.

19.SOUZA, Z. M.; MARQUES JÚNIOR, J.; PEREIRA, G. T.; BENTO, M. J. C. Variabilidade espacial de atributos físicos de um Latossolo Vermelho sob cultivo de cana-de-açúcar. Revista Brasileira de Engenharia Agrícola e Ambiental, Campina Grande, v. 8, n. 1, p.51-58, 2004.

20.SOUZA, Z. M.; CAMPOS, M. C. C.; CALVACANTE, I. H. L.; MARQUES JÚNIOR, J.; CESARIN, L. G.; SOUZA, S. R. Dependência espacial da resistência do solo à penetração e do teor de água do solo sob cultivo contínuo de cana-de-açúcar. Ci. Rural, v.36, p.128-134, 2006

21.STOLF, R. Teoria e teste experimental de fórmulas de transformação dos dados de penetrômetro de impacto em resistência do solo. Revista Brasileira de Ciência do Solo, Viçosa, MG, v.15, p.229-235, 1991.

22.UNESP / UNIVERSIDADE ESTADUAL PAULISTA. Faculdade de Engenharia. Departamento de Fitossanidade, Engenharia Rural e Solos. Área de Hidráulica e Irrigação. Dados agrometeorológicos. Disponível em: http://www.agr.feis.unesp.br/ clima.php. Acesso em: 14 nov. 2008.

Recebido em 11/08/2011 Aceito em 05/02/2013 